\title{
Methionine-choline deprivation alters liver and brain acetylcholinesterase activity in C57BL6 mice
}

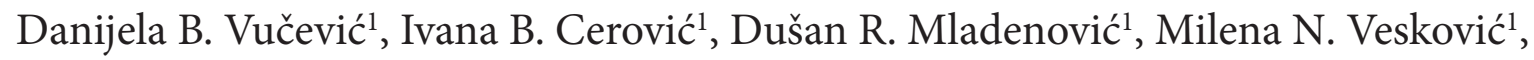 \\ Ivana Stevanović 2 , Bojan Z. Jorgačević ${ }^{1}$, Rada Ješić Vukićevićs ${ }^{3}$ and Tatjana S. Radosavljević ${ }^{1}$ \\ ${ }^{1}$ Institute of Pathophysiology "Ljubodrag Buba Mihailović«, Faculty of Medicine, University of Belgrade, Dr Subotića 9, \\ 11000 Belgrade, Serbia \\ ${ }^{2}$ Institute for Medical Research, Military Medical Academy,11000 Belgrade, Serbia \\ ${ }^{3}$ Institute of Digestive Diseases, Clinical Centre of Serbia, 11000 Belgrade, Serbia
}

\begin{abstract}
Choline and methionine are precursors of acetylcholine, whose hydrolysis is catalyzed by acetylcholinesterase (AChE). Considering the possibility of their common deficiency, we investigated the influence of methionine-choline deprivation on AChE activity in liver and various brain regions (hypothalamus, hippocampus, cerebral cortex and striatum) in mice fed with methionine-choline deficient (MCD) diet. Male C57BL/6 mice $(n=28)$ were randomly and equally divided into following groups: control group fed with standard diet for 6 weeks $(\mathrm{C})$ and groups fed with $\mathrm{MCD}$ diet for 2 weeks (MCD2), 4 weeks (MCD4) and for 6 weeks (MCD6). After the diet, mice were sacrificied and AChE activity in liver and brain was determined spectrophotometrically. Hepatic AChE activity was higher in MCD2, MCD4 and MCD6 compared to control $(p<0.01)$, with most prominent increase in MCD6. AChE activity in hypothalamus was higher in MCD4 and MCD6 vs. control $(p<$ 0.05 and $p<0.01$, respectively), as well as in MCD6 compared to MCD4 $(p<0.01)$. In hippocampus, increase in AChE activity was shown in MCD6 compared to control $(p<0.01)$. In cortex and striatum, increase in AChE activity was noted in MCD6 compared to control $(p<0.05)$. Our findings indicate the increase of hepatic and brain AChE activity in mice caused by methionine-choline deprivation.
\end{abstract}

Key words: Acetylcholinesterase - Brain — Liver - Methionine-choline deficient (MCD) diet Mice

\begin{abstract}
Abbreviations: $\mathrm{ACh}$, acetylcholine; $\mathrm{AChE}$, acetylcholinesterase; $\mathrm{CNS}$, central nervous system; $\mathrm{GSH}$, glutathione; MCD, methionine-choline deficient: NAFLD, nonalcoholic fatty liver disease; NF- $\mathrm{kB}$, nuclear factor kappa B; RNS, reactive nitrogen species; ROS, reactive oxygen species; TNFa, tumor necrosis factor $\alpha$.
\end{abstract}

\section{Introduction}

Methionine is the major dietary source of methyl groups, since this essential amino acid is the immediate precursor of S-adenosylmethionine (SAM), which is the universal donor in the processes of transmethylation (Stead et al. 2006; Anderson et al. 2012; Guéant et al. 2013). Nevertheless, methylation

Correspondence to: Tatjana Radosavljević, Institute of Pathophysiology, Faculty of Medicine, University of Belgrade, Dr Subotića 9, 11000 Belgrade, Serbia

E-mail: tanjamm@med.bg.ac.rs reactions play major role in biosynthesis of lipids, regulation of metabolic pathways and detoxification processes (Stead et al. 2006). Recent studies indicate that endogenous synthesis of methionine is a major event in the cell life (Anderson et al. 2012; Guéant et al. 2013). It is known that endogenous methionine has dual source, the remethylation pathway and the degradation of endogenous or food proteins (Guéant et al. 2013). Homocysteine is converted to methionine upon the action of methionine synthase, with folic acid as the methyl-donor and vitamin $\mathrm{B}_{12}$ as the methionine synthase co-factor (Finkelstein 2003). Alternative metabolic pathway is interaction of homocysteine and betaine, an oxidative 
product of choline, which occurs only in liver, kidney and lens (Finkelstein 1990; Ueland 2011). Therefore, choline, methionine and folate metabolism interact at the point at which homocysteine is converted to methionine (Penry and Manore 2008). Deficiency of vitamin $B_{12}$, usually affiliated with folate deficiency as well, is mainly observed during pregnancy or aging (Yajnik and Deshmukh 2012). Combined vitamin $\mathrm{B}_{12}$ and folate deficiency is also associated with Alzheimer and Parkinson diseases, thrombosis, stroke and myocardial infarction (Selhub 2008; Smith 2008).

Choline is recognized as an essential nutrient, due to its important role in cholinergic neurotransmission (acetylcholine synthesis), synthesis of phospholipids in cell membranes and cell-membrane signaling, as well as in lipid-cholesterol metabolism and methylation reactions (Penry and Manore 2008; Zeisel and da Costa 2009). Most of the choline in organism is found in phospholipids, such as phosphatidylcholine and sphingomyelin (Zeisel and da Costa 2009). Though representing a smaller proportion of the total choline pool, important metabolites of choline include platelet-activating factor, choline plasmalogens, lysophosphatidylcholine, phosphocholine, glycerophosphocholine and betaine (Zeisel 2000). In clinical practice, choline deficiency may be a consequence of physiological conditions (pregnancy and lactation), as well as different disorders (alcoholism, malnutrition, fatty liver and muscle damage) (Li and Vance 2008).

Choline is a precursor of acetylcholine (ACh), an important neurotransmitter in the peripheral and central nervous system (CNS) (Parson et al. 1993). ACh is released by neurons in many areas of the brain (the large pyramidal cells of motor cortex, several different types of neurons in the basal ganglia, as well as motor neurons that innervate skeletal muscles, preganglionic neurons of the autonomic nervous system, postganglionic neurons of the parasympathetic nervous system, etc) (Prado et al. 2002). ACh is also needed for normal processes of learning, memory and behavior (Fadda et al. 2000; Hironaka et al. 2001; Cooper et al. 2003; Stefanello et al. 2007; Alvarez et al. 2009; Zeisel and da Costa 2009). Furthermore, there is evidence that ACh has antiinflammatory effects, which is mediated primarily through nicotinic ACh receptors expressed on macrophages, so ACh receptors modulate interactions between the nervous system and the immune system (Wang et al. 2011; Das 2012). ACh reduces nuclear factor kappa B (NF- $\mathrm{B}$ ) activation and decreases production of inflammatory cytokines (Pavlov and Tracey 2004). Besides, nonneuronal cholinergic system also plays a significant metabolic role in erythrocytes (De Almeida and Saldanha 2010), lymphocytes (Reardon et al. 2013), skin (Kurzen and Schallreuter 2004) and liver (García-Ayllón et al. 2012).

Acetylcholinesterase (AChE; EC 3.1.1.7) is a crucial membrane-bound enzyme involved in cholinergic neuro- transmission, which rapidly hydrolyzes ACh in particular (Cooper et al. 2003). Consequentially, the activity duration of this neurotransmitter at the synaptic clefts highly depends on AChE activity (Prado et al. 2002). AChE is distributed in cholinergic neurons and widely throughout the body, mainly in erythrocytes, lymphocytes, liver and serum (Prado et al. 2002; Cooper et al. 2003). Apart from its catalytic activity in hydrolyzing ACh, AChE affects cell proliferation, differentiation and responses to various insults, including oxidative stress (Grisaru et al. 1999; Bond et al. 2006; Bond and Greenfield 2007; Valko et al. 2007; Ghareeb and Hussein 2008; Ghareeb et al. 2010, 2011). It also performs nonenzymatic, trophic (e.g. stimulation of neuritogenesis and remodeling) and neuromodulatory (promotion of long-term functional changes in the CNS) functions (Silman and Sussman 2005; Gralewicz 2006; Anglister et al. 2008; Greenfield et al. 2008; Vučević et al. 2009).

Methionine-choline deficient (MCD) diet is proven to be one of the most reliable experimental models for nonalcoholic fatty liver disease (NAFLD) (Rinella et al. 2008; Itagaki et al. 2013; Stankovic et al. 2014; Machado et al. 2015). Therefore, MCD mice model of NAFLD is the base of many other studies for examination contributing metabolic changes, functional disorders or diagnostic options considering this disease (Canet et al. 2014; Lee et al. 2015; Luther et al. 2015; Ryu et al. 2015). On the other hand, in clinical practice, combined methionine and choline deficiency might occur in different pathological and physiological conditions, such as malnutrition, vegetarianism, malabsorption syndrome, Crohn's disease, as well as pregnancy, lactation and use of some drugs (Zeisel and da Costa 2009).

Considering the physiological bonds of methionine and choline with acetylcholinesterase, reliability of MCD experimental mice model and clinical significance of methionine and choline deficiency, the aim of the present study was to investigate the influence of methionine-choline deprivation on AChE activity in liver and various brain regions (hypothalamus, hippocampus, cerebral cortex and striatum) in mice fed with MCD diet.

\section{Materials and Methods}

\section{Animals}

The experiment was performed on male C57BL/ 6 mice, $6-8$ weeks old, weighting on the average $23 \pm 3 \mathrm{~g}$, which were raised at Military Medical Academy, Belgrade, Serbia. Animals were kept in individual cages under standard laboratory conditions (ambient temperature $22 \pm 2{ }^{\circ} \mathrm{C}$, relative humidity $50 \pm 10 \%, 12 / 12 \mathrm{~h}$ dark/light cycle with lights turned on at 9.00 a.m.) with free access to tap water and appropriate food. All experimental procedures were in full 
compliance with Directive of the European Parliament and of the Council (2010/63EU) and approved by the Ethical Commitee of the University of Belgrade, Serbia (Permission $\mathrm{N}^{\mathrm{O}} 695 / 2$ ).

\section{Experimental design}

All animals $(n=28)$ were randomly divided into following groups: 1. Control group fed with standard diet (960441-MP Biomedical, CA, USA) for 6 weeks (C; $n=7)$. 2. Group fed with MCD diet for 2 weeks (MCD2; $n=7)$. 3. Group fed with MCD diet for 4 weeks (MCD4; $n=7)$. 4. Group fed with MCD diet for 6 weeks (MCD6; $n=7$ ). Standard diet contained $2 \mathrm{~g} / \mathrm{kg}$ choline chloride and $3 \mathrm{~g} / \mathrm{kg}$ methionine, while MCD diet had the same composition as standard chow without methionine and choline and with expense of sucrose (22.76\%) (960439-MP Biomedical, CA, USA).

On the day prior to sacrifice, mice were fasted overnight. After 2, 4 and 6 weeks on diet treatment, mice were sacrificied by exsanguination in ketamine anesthesia $(100 \mathrm{mg} / \mathrm{kg}$ intraperitoneally). Liver and brain samples (hypothalamus, hippocampus, cerebral cortex and striatum) were taken for determination of AChE activity.

\section{Sample preparation}

After decapitation, the brains were quickly removed and four brain regions (hypothalamus, hippocampus, cerebral cortex and striatum) were immediately homogenized in cold-buffered sucrose medium $(0.25 \mathrm{M}$ sucrose, $10 \mathrm{mM}$ $\mathrm{K} / \mathrm{NaPO}_{4}, 1 \mathrm{mM}$ ethylenediaminetetraacetic acid (EDTA), pH 7.0) (Serva Feinbiochemica, Heidelberg, New York, USA). After homogenization, the crude synaptosomal fraction for determination of AChE activity was prepared according to the method of Whittaker and Barker (Whittaker and Barker 1972). Homogenates were centrifuged twice at $1000 \times g$ for $15 \mathrm{~min}$ at $4^{\circ} \mathrm{C}$. The supernatant was further centrifuged at $20.000 \times g$ for $20 \mathrm{~min}$. Supernatant obtained by this procedure represents crude synaptosomal fraction containing membrane vesicles (microsomes) from smooth and rough endoplasmic reticulum, Golgi and plasma membrane and all of the soluble components of the cytoplasm (Whittaker and Barker 1972).

Liver samples were homogenized on ice, in coldbuffered 0.25 M sucrose medium (Serva Feinbiochemica, Heidelberg, New York, USA), $10 \mathrm{mM}$ phosphate buffer (pH 7.0), and $1 \mathrm{mM}$ EDTA (Sigma chemicals Ltd, St. Louis, Missouri, USA). The homogenates were centrifuged at $2000 \times g$ for $15 \mathrm{~min}$ at $4^{\circ} \mathrm{C}$. Crude sediments were dissolved in a sucrose medium and centrifuged. The supernatants were transferred into the tubes and centrifuged at $3200 \times g$ for $30 \mathrm{~min}$ at $4^{\circ} \mathrm{C}$. Obtained sediments were dissolved in deionized water. After 1 hour of incubation, the samples were centrifuged at $3000 \times g$ for $15 \mathrm{~min}$ at $4^{\circ} \mathrm{C}$, and supernatants were stored at $-70^{\circ} \mathrm{C}$ for 3 days before starting measurement.

\section{Determination of AChE activity}

AChE activity, expressed as $\mathrm{mol} \cdot \mathrm{mg} \mathrm{prot.}^{-1} \mathrm{~min}^{-1} \times 10^{-4}$ was assayed by spectrophotometric method of Ellman et al. (1961) using acetylthiocholine iodide as a substrate in homogenates of liver, hypothalamus, hippocampus, cerebral cortex and striatum. Each sample was taken from one animal and assayed in duplicate. The rate of hydrolysis of acetylthiocholine iodide was measured at $412 \mathrm{~nm}$ through the release of the thiol compound which, when reacted with 5,5'-dithiobis2-nitrobenzoic acid (DTNB), produced the absorbing compound thionitrobenzoic acid (Ellman et al. 1961).

\section{Statistical analysis}

All results are expressed as means $\pm \mathrm{SD}$. As the normal distribution of parameters was confirmed by KolmogorovSmirnov test, one-way analysis of variance (ANOVA) with

Table 1. The effects of methionine-choline deficient (MCD) diet on the acetylcholinesterase (AChE) activity in liver and brain (hypothalamus, hippocampus, cortex and striatum) after two (MCD2), four (MCD4) and six (MCD6) weeks

\begin{tabular}{lcccl}
\hline & \multicolumn{3}{c}{ Groups } \\
\cline { 2 - 5 } & Control & MCD2 & MCD4 & MCD6 \\
\hline Liver & $43.9 \pm 21.0$ & $200.7 \pm 82.6^{* *}$ & $209.2 \pm 70.6^{* *}$ & $334.7 \pm 112.8^{* * \# \#+}$ \\
Hypothalamus & $217.2 \pm 47.5$ & $245.6 \pm 50.4$ & $287.0 \pm 45.4^{*}$ & $597.3 \pm 166.3^{* *}$ \\
Hippocampus & $222.4 \pm 60.9$ & $237.5 \pm 42.3$ & $278.9 \pm 153.0$ & $651.7 \pm 146.4^{* *}$ \\
Cortex & $217.0 \pm 81.4$ & $318.8 \pm 73.9$ & $190.9 \pm 50.3$ & $363.2 \pm 82.9^{*}$ \\
Striatum & $322.9 \pm 101.0$ & $358.1 \pm 39.0$ & $239.7 \pm 146.4$ & $446.8 \pm 79.1^{*}$ \\
\hline
\end{tabular}

Data are presented as means \pm standard deviation (SD) ( $\mu$ mol acetylcholine/min/g proteins). Significance of the difference was estimated by using analysis of variance (ANOVA) with Tukey post-hoc t-test. ${ }^{*} p<0.05,{ }^{* *} p<0.01 v$ s. control group; ${ }^{\# \#} p<0.01 \mathrm{MCD} 2$ group; H $p<0.01$ vs. MCD4 group. 
Tuckey's post hoc test was used for testing the difference among groups. The difference was considered significant if $p<0.05$. For statistical analysis computer software SPSS 15.0 was used.

\section{Results}

The levels of AChE activity in liver and four brain regions hypothalamus, hippocampus, cortex and striatum, after two, four and six weeks of methionine-choline deficient diet are presented in Table 1.

Hepatic AChE activity was significantly higher in MCD2 (200.7 \pm 82.6), MCD4 (209.2 \pm 70.6$)$ and MCD6 (334.7 \pm $112.8)$ in comparison with control $(43.9 \pm 21.0)(p<0.01)$. The most prominent increase in activity of this enzyme was evident in mice fed with MCD for six weeks, which resulted in significant difference between MCD6 compared to both MCD2 and MCD4 (Fig. 1).

Further analysis revealed that activity of AChE in hypothalamus was significantly higher in MCD4 (287.0 \pm 45.4$)$ and MCD6 (597.3 \pm 166.3$) v s$. control $(p<0.05$ and $p<0.01$, respectively). Also, the significant increase in AChE activity was found in MCD6 compared to MCD4 in this region $(p<0.01)$ (Fig. 2).

Following the time-depending rise, AChE activity in hippocampus has shown highly significant increase in MCD6 $(651.7 \pm 146.4)$ in comparison with control $(222.4 \pm 60.9)$ $(p<0.01)$ (Fig. 2).

On the other hand, in cortex and striatum, the change of AChE activity has shown slightly different pattern. Although

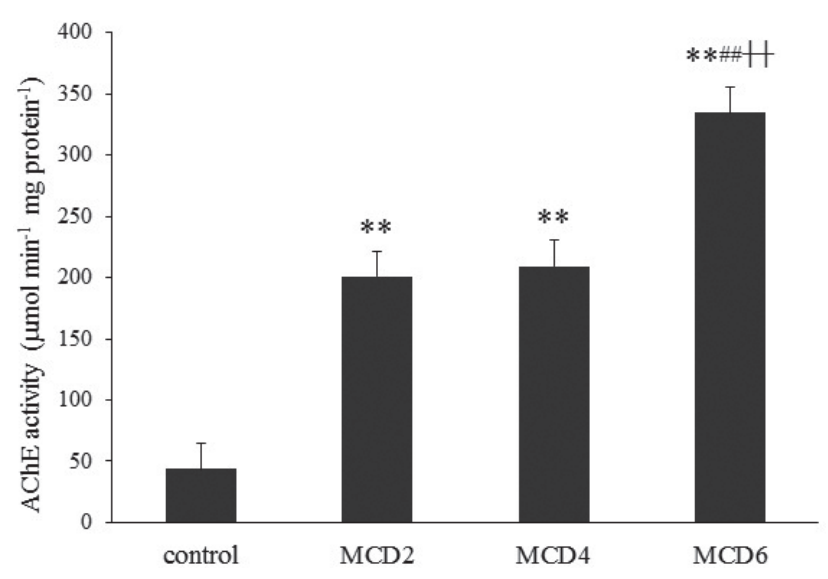

Figure 1. The effects of methionine-choline deficient (MCD) diet on acetylcholinesterase (AChE) activity in liver after two (MCD2), four (MCD4) and six (MCD6) weeks. Significance of the difference was estimated by using analysis of variance (ANOVA) with Tuckey post-hoc $t$-test $\left({ }^{* *} p<0.01\right.$ vs. control group; ${ }^{\# \#} p<0.01$ vs. MCD2; ${ }^{+} p<0.01$ vs. MCD4).

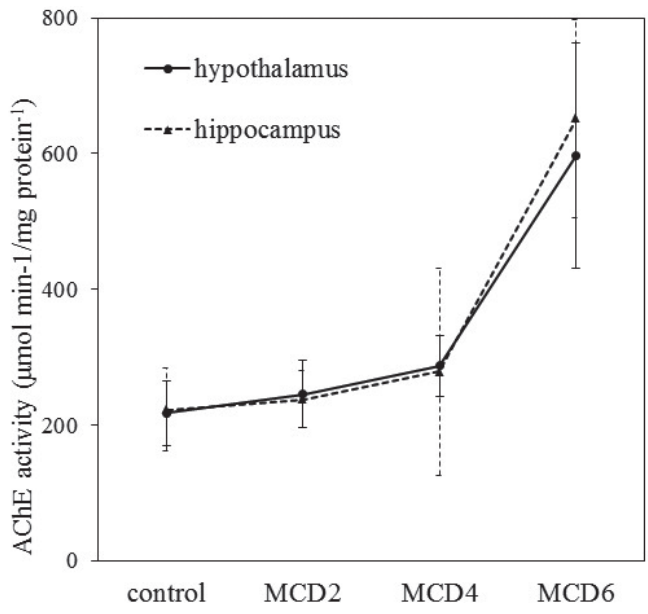

Figure 2. The effects of methionine-choline deficient (MCD) diet on acetylcholinesterase (AChE) activity in hypothalamus and hippocampus after two (MCD2), four (MCD4) and six (MCD6) weeks. Significance of the difference was estimated by using analysis of variance (ANOVA) with Tukey post-hoc t-test $\left({ }^{*} p<0.05\right.$, ${ }^{* *} p<0.01$ vs. control group; ${ }^{+} p<0.01$ vs. MCD4).

the increase in activity of this enzyme was registered in MCD2 (318.8 \pm 73.9 and $358.1 \pm 39.0)$, as well as decline in MCD4 (190.9 \pm 50.3 and $239.7 \pm 146.4)$, no significance was proven between these groups and control in both brain regions $(217.0 \pm 81.4$ and $322.9 \pm 101.0)(p>0.05)$ (Fig. 3). The significant increase in AChE activity in cortex and striatum was noted in MCD6 (363.2 \pm 82.9 and $446.8 \pm 79.1)$ compared to control $(p<0.05)$.

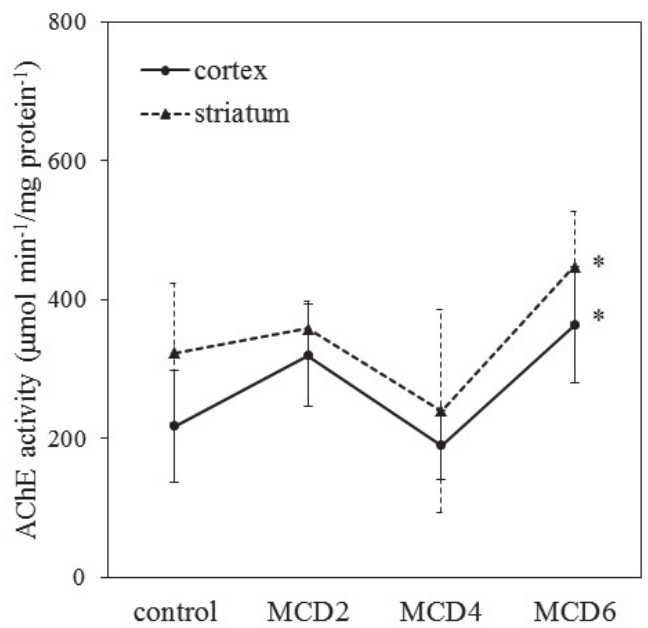

Figure 3. The effects of methionine-choline deficient (MCD) diet on acetylcholinesterase (AChE) activity in cortex and striatum after two (MCD2), four (MCD4) and six (MCD6) weeks. Significance of the difference was estimated by using analysis of variance (ANOVA) with Tukey post-hoc $t$-test $\left({ }^{\star} p<0.05 v\right.$ s. control group). 


\section{Discussion}

Considering their wide-ranging roles in human metabolism, methionine and choline deficiency contributes to many diseases (malnutrition, malabsorption syndrome, Crohn`s disease), as well as in pregnancy, lactation, vegetarianism and use of some drugs (Zeisel and da Costa 2009). However, the exact mechanism by which methionine-choline deficiency alters neurotransmitter equilibrium in the liver and brain tissue is still an insufficiently explored field. From a scientific point of view, our results represent the important findings, since the influence of methionine-choline deprivation on the AChE activity has not been examined neither in vitro nor in vivo experiments.

Our investigation has shown that AChE activity in liver was significantly higher in MCD2, MCD4 and MCD6 in comparison with control $(p<0.01)$ (Fig. 1), where the most prominent increase was evident after six weeks (Fig. 1). AChE expression in liver tissue is closely interconnected with oxidative stress (Ghareeb et al. 2011). Methionine deficiency results in decrease of cysteine, the major precursor of glutathione (GSH), which is the main cellular antioxidant, while choline deprivation decreases phosphatidylcholine portion in very low-density lipoprotein particles (VLDL), with consequential accumulation of triacylglycerol (TAG) in liver (Marcolin et al. 2011). However, various pathophysiological processes in liver were recognized as consequences of oxidative stress (Bianchi et al. 2000; Jorgačević et al. 2014). Oxidants react with proteins, nucleic acids and lipids, causing lipid peroxidation, membrane damage and loss of cellular calcium homeostasis, which in turn leads to enhanced AChE release (Bond and Greenfield 2007; Valko et al. 2007; Ghareeb et al. 2011). There is a scientifically-based assumption that oxidative stress in relation with methionine-choline deprivation contributes to alteration of AChE activity in our experiment.

In current study, increase in hepatic AChE activity is in agreement with hypothesis that this enzyme may serve as marker of inflammation in liver (Das 2012). MCD animal model, which is used in this experiment, is considered convenient basis for examining nonalcoholic steatohepatitis (NASH) (Marcolin et al. 2011). Increased concentration of AChE lowers ACh level, leading to reduction or absence of its antiinflammatory activity (Das 2012). Additionally, various studies examine a possible role of hepatic AChE on inhibition of circulating ACh, maintenance of cellular signal transduction and stimulation of different types of apoptosis (Gómez et al. 2000; Silman and Sussman 2005; Gralewicz 2006; García-Ayllón et al. 2012; Zhang and Greenberg 2012). Besides, methionine deprivation stimulates synthesis and release of tumor necrosis factor a (TNFa) and other cytokines, which also contributes to inflammation (McClain et al. 2002).
Our study indicates that nutritional methionine-choline deprivation leads to increase in AChE activity in all investigated brain regions (hypothalamus, hippocampus, cerebral cortex and striatum) (Figures 2 and 3). In hypothalamus, the increase in AChE activity can be observed already in fourth week (Fig. 2). On the contrary, in other brain regions, the raise of AChE activity is not detected until sixth week of experimental procedure (Figures 2 and 3). Having in mind that choline administration leads to increase in brain AChE activity, due to enhancement of its precursor concentration (induction of ACh synthesis) or central muscarinic response (Kilbinger and Kruel 1981), it is expected that choline deprivation would induce decrease in AChE activity. However, similar to our findings, published data indicate an increase in AChE activity, especially during prolonged utilization of choline deficient diet (Bianchi et al. 2000; Liapi et al. 2008, 2010). Possible explanation for the increase in AChE activity may be related to methionine effect. Methionine deprivation has ability to reduce GSH production, with consequent decline of antioxidant capacity (Bianchi et al. 2000), while higher levels of reactive oxygen and nitrogen species (ROS and RNS), impair synaptic transmission through oxidation of key synaptic proteins and raise AChE activity (Bond and Greenfield 2007; Ghareeb and Hussein 2008; Ghareeb et al. 2010; Xia et al. 2011). Hypothetically, potential explanation for the increase of AChE activity might also be compensatory hyperactivation of the enzyme in order to utilize the limited amount of the substrate, ACh, caused by the lack of choline. However, this well-known homeostatic mechanism would need to be examined and proven in this particular process. Besides, oxidative stress mediated by dietary choline deprivation has been implicated as a pathway for stimulating multiple pathophysiological states with significant neurotoxic consequences (Zeisel 2000; Liapi et al. 2008; Ghareeb et al. 2011; Jorgačević et al. 2014).

On the other hand, the increase in AChE activity in present MCD animal model might potentially refer to various molecular forms of this enzyme (Grisaru et al. 1999; Perrier et al. 2005; Vučević et al. 2009). AChE was found in different molecular types, depending on alternative splicing of its transcripts and association with structural proteins (De Oliveira et al. 2012). For example, tetramers of the "tailed" variant (AChE-T), constitute the main form of AChE in the mammalian brain, while in the mouse brain, stress and anticholinesterase inhibitors induce the expression of unspliced "readthrough" variant (AChE-R) mRNA which produces a monomeric form (Perrier et al. 2005). Choline deficiency caused the increase of AChE expression in crucial rat brain regions (hippocampus, hypothalamus, frontal cortex and pons) to a diverse extent (Liapi et al. 2009). Taking these facts into consideration, results of our study may be the consequence of competition between AChE variants and their 
homologs for interactions with the corresponding protein partner in investigated tissues.

In some metabolic disorders, alteration of AChE expression is specific for certain brain regions, which can be explained by interaction of ACh with other neurotransmitters for maintenance of physiological processes in those brain structures (Carageorgiou et al. 2007). There are numerous evidences that choline dietary restriction is responsible for disturbance of cholinergic neurotransmission in brain tissue, primarily in hippocampus, with consequent learning, memory and behavior disorders (Fadda et al. 2000; Hironaka et al. 2001; Hossain et al. 2005; Stefanello et al. 2007; Selhub 2008; Smith 2008; Trevisan et al. 2008; Alvarez et al. 2009; Querfurth and La Ferla 2010).

As it was previously mentioned, not any study has been conducted on methionine-choline deficiency mechanism involving cholinergic system. Based on our results, for the first time it can be confirmed the influence of methioninecholine deprivation on hepatic and brain AChE activity in mice. Our findings have shown that, due to methioninecholine nutritional deficiency, AChE activity in liver, hypothalamus, hippocampus, cerebral cortex and striatum remains the same or increases, depending on the duration of treatment. However, the exact mechanisms of these time-depending and region-specific differences in AChE expression will require further investigation.

Acknowledgements. This research was financially supported by the Ministry of Education, Science and Technological Development of Republic of Serbia. Grant no.175015, and Ministry of Defence MFVMA/2/12-14.

Conflict of interest. The authors declared no conflicts of interest.

\section{References}

Alvarez E. O., Beauquis J., Revsin Y., Banzan A. M., Roig P., De Nicola A. F., Saravia F. (2009): Cognitive dysfunction and hippocampal changes in experimental type 1 diabetes. Behav. Brain. Res. 198, 224-230 http://dx.doi.org/10.1016/j.bbr.2008.11.001

Anderson O. S., Sant K. E., Dolinoy D. C. (2012): Nutrition and epigenetics: an interplay of dietary methyl donors, one-carbon metabolism and DNA methylation. J. Nutr. Biochem. 23, 853-859 http://dx.doi.org/10.1016/j.jnutbio.2012.03.003

Anglister L., Etlin A., Finkel E., Durrant A. R., Lev-Tov A. (2008): Cholinesterases in development and disease. Chem. Biol. Interact. 175, 92-100 http://dx.doi.org/10.1016/j.cbi.2008.04.046

Bianchi G., Brizi M., Rossi B., Ronchi M., Grossi G., Marchesini G. (2000): Synthesis of glutathione in response to methionine load in control subjects and in patients with cirrhosis. Metabolism 11, 1434-1439 http://dx.doi.org/10.1053/meta.2000.16554

Bond C. E., Patel P., Crouch L., Tetlow N., Day T., Abu-Hayyeh S., Williamson C., Greenfield S. A. (2006): Astroglia up-regulate transcription and secretion of ,readthrough' acetylcholinesterase following oxidative stress. Eur. J. Neurosci. 24, 381-386 http://dx.doi.org/10.1111/j.1460-9568.2006.04898.x

Bond C. E., Greenfield S. A. (2007): Multiple cascade effects of oxidative stress on astroglia. Glia. 55, 1348-1361 http://dx.doi.org/10.1002/glia.20547

Carageorgiou H., Pantos C., Zarros A. (2007): Changes in acetylcholinesterase, $\mathrm{Na}+\mathrm{K}+$-ATPase, and $\mathrm{Mg} 2+-$ ATPase activities in the frontal cortex and the hippocampus of hyper-and hypothyroid adult rats. Metabolism 56, 1104-1110 http://dx.doi.org/10.1016/j.metabol.2007.04.003

Canet M. J., Hardwick R. N., Lake A. D., Dzierlenga A. L., Clarke J. D., Cherrington N. J. (2014): Modeling human nonalcoholic steatohepatitis-associated changes in drug transporter expression using experimental rodent models. Drug. Metab. Dispos. 42, 586-595 http://dx.doi.org/10.1124/dmd.113.055996

Cooper J. R., Bloom F. E., Roth R. H. (2003): Acetylcholine. The Biochemical Basis of Neuropharmacology. Oxford University Press, New York

Das N. U. (2012): Acetylcholinesterase and butyrylcholinesterase as markers of low-grade systemic inflammation. Annal. Hepatol. 11, 409-411

De Almeida J. P., Saldanha C. (2010): Nonneuronal cholinergic system in human erythrocytes: biological role and clinical relevance. J. Membr. Biol. 234, 227-234 http://dx.doi.org/10.1007/s00232-010-9250-9

De Oliveira P., Gomes A. Q., Pacheco T. R., Vitorino de Almeida V., Saldanha C., Calado A. (2012): Cell-specific regulation of acetylcholinesterase expression under inflammatory conditions. Clin. Hemorheol. Microcirc. 51, 129-137

Ellman G. L., Courtney K. D., Andres V. Jr., Feather-Stone R. M. (1961): A new and rapid colorimetric determination of acetylcholinesterase activity. Biochem. Pharmacol. 7, 88-95 http://dx.doi.org/10.1016/0006-2952(61)90145-9

Fadda F., Cocco S., Stancampiano R. (2000): Hippocampal acetylcholine release correlates with spatial learning performance in freely moving rats. Neuroreport 11, 2265-2269 http://dx.doi.org/10.1097/00001756-200007140-00040

Finkelstein J. D. (1990): Methionine metabolism in mammals. J. Nutr. Biochem. 1, 228-237 http://dx.doi.org/10.1016/0955-2863(90)90070-2

Finkelstein J. D. (2003): Methionine metabolism in liver diseases. Am. J. Clin. Nutr. 77, 1094-1095

García-Ayllón M. S., Millán C., Serra-Basante C., Bataller R., SáezValero J. (2012): Readthrough acetylcholinesterase is increased in human liver cirrhosis. PloS One 7, e44598 http://dx.doi.org/10.1371/journal.pone.0044598

Ghareeb D., Hussein H. (2008): Vanadium improves brain acetylcholinesterase activity on early stage alloxan-diabetic rats. Neurosci. Lett. 436, 44-47 http://dx.doi.org/10.1016/j.neulet.2008.02.073

Ghareeb D., Hussein H., Khalil A., Saadani M., Ali A. (2010): Toxic effects of lead exposure on the brain of rats: Involvement of oxidative stress, inflammation, acetylcholinesterase, and the 
beneficial role of flaxseed extract. Toxicol. Environ. Chem. 92, 187-195 http://dx.doi.org/10.1080/02772240902830631

Ghareeb D. A., Hafez H. S., Hussein H. M., Kabapy N. F. (2011): Non-alcoholic fatty liver induces insulin resistance and metabolic disorders with development of brain damage and dysfunction. Metab. Brain Dis. 26, 253-267 http://dx.doi.org/10.1007/s11011-011-9261-y

Gómez J. L., Garcia-Ayllon M. S., Campoy F. J., Vidal C. J. (2000): Muscular dystrophy alters the processing of light acetylcholinesterase but not butyrylcholinesterase forms in liver of Lama2(dy) mice. J. Neurosci. Res. 62, 134-145 http://dx.doi.org/10.1002/1097-4547(20001001)62:1<134::AID-JNR14>3.0.CO;2-T

Gralewicz S. (2006): Possible consequences of acetylcholinesterase inhibition in organophosphate poisoning. Discussion continued. Med. Pr. 57, 291-302

Greenfield S. A., Zimmermann M., Bond C. E. (2008): Nonhydrolytic functions of acetylcholinesterase. The significance of C-terminal peptides. FEBS. J. 275, 604-611 http://dx.doi.org/10.1111/j.1742-4658.2007.06235.x

Grisaru D., Sternfeld M., Eldor A., Glick D., Soreq H. (1999): Structural roles of acetylcholinesterase variants in biology and pathology. Eur. J. Biochem. 264, 672-686 http://dx.doi.org/10.1046/j.1432-1327.1999.00693.x

Guéant J. L., Caillerez-Fofou M., Battaglia-Hsu S., Alberto J. M., Freund J. N., Dulluc I., Adjalla C., Maury F., Merle C., Nicolas J. P., Namour F., Daval J. L. (2013): Molecular and cellular effects of vitamin B12 in brain, myocardium and liver through its role as co-factor of methionine synthase. Biochimie 95, $1033-1040$ http://dx.doi.org/10.1016/j.biochi.2013.01.020

Hironaka N., Tanaka K., Izaki Y., Hori K., Nomura M. (2001): Memory-related acetylcholine efflux from rat prefrontal and hippocampus: A microdialysis study. Brain Res. 901, 143-150 http://dx.doi.org/10.1016/S0006-8993(01)02338-1

Hossain M. M., Suzuki T., Sato I., Takewaki T., Suzuki K., Kobayashi H. (2005): Neuromechanical effects of pyrethroids, allethrin, cyhalothrin and deltamethrin on the cholinergic processes in rat brain. Life Sci. 77, 795-807 http://dx.doi.org/10.1016/j.lfs.2005.01.014

Itagaki H., Shimizu K., Morikawa S., Ogawa K., Ezaki T. (2013): Morphological and functional characterization of non-alcoholic fatty liver disease induced by a methionine-choline-deficient diet in C57BL/6 mice. Int. J. Clin. Exp. Pathol. 6, 2683-2696

Jorgačević B., Mladenović D., Ninković M., Prokić V., Stanković M. N., Aleksić V., Cerović I., Vukićević R. J., Vučević D., Stanković M., Radosavljević T. (2014): Dynamics of oxidative/nitrosative stress in mice with methionine-choline-deficient dietinduced nonalcoholic fatty liver disease. Hum. Exp. Toxicol. 33, 701-709 http://dx.doi.org/10.1177/0960327113506723

Kilbinger H., Kruel M. R. (1981): Choline inhibits acetylcholine release via presynaptic muscarinic receptors. NaunynSchmiedebergis Arch. Pharmacol. 316, 131-134

Kurzen H., Schallreuter K. U. (2004): Novel aspects in cutaneous biology of acetylcholine synthesis and acetylcholine receptors. Exp. Dermatol. 4, 27-30 http://dx.doi.org/10.1111/j.1600-0625.2004.00258.x

Lee S. J., Kang J. H., Iqbal W., Kwon O. S. (2015): Proteomic analysis of mice fed methionine and choline deficient diet reveals marker proteins associated with steatohepatitis. PLoS One 10, e0120577 http://dx.doi.org/10.1371/journal.pone.0120577

Li Y., Vance D. (2008): Phosphatidylcholine and choline homeostasis. J. Lipid. Res. 49, 1187-1194 http://dx.doi.org/10.1194/jlr.R700019-JLR200

Liapi C., Feskou I., Zarros A., Carageorgiou H., Galanopoulou P., Tsakiris S. (2008): Equilibrated diet restores the effects of early age choline-deficient feeding on rat brain antioxidant status and enzyme activities: the role of homocysteine, L-phenylalanine and L-alanine. Metab. Brain Dis. 23, 289-301 http://dx.doi.org/10.1007/s11011-008-9097-2

Liapi C., Kyriakaki A., Zarros A. (2009): Effects of adult-onset choline deprivation on the activities of acetylcholinesterase, $(\mathrm{Na}+, \mathrm{K}+)$ - and $\mathrm{Mg} 2+-\mathrm{ATPase}$ in crucial rat brain regions. Food. Chem. Toxicol. 47, 82-85 http://dx.doi.org/10.1016/j.fct.2008.10.012

Liapi C., Kyriakaki A., Zarros A. (2010): Choline-deprivation alters crucial brain enzyme activities in a rat model of diabetic encephalopathy. Metab. Brain. Dis. 25, 269-276 http://dx.doi.org/10.1007/s11011-010-9205-y

Luther J., Garber J. J., Khalili H., Dave M., Bale S. S., Jindal R., Motola D. L., Luther S., Bohr S., Jeoung S. W. et al. (2015): Hepatic injury in nonalcoholic steatohepatitis contributes to altered intestinal permeability. Cell. Mol. Gastroenterol. Hepatol. 1, 222-232 http://dx.doi.org/10.1016/j.jcmgh.2015.01.001

Machado M. V., Michelotti G. A., Xie G., Almeida Pereira T., Boursier J., Bohnic B., Guy C. D., Diehl A. M. (2015): Mouse models of diet-induced nonalcoholic steatohepatitis reproduce the heterogeneity of the human disease. PLoS One. 10, e0127991 http://dx.doi.org/10.1371/journal.pone.0127991

Marcolin E., Forgiarini L. F., Tieppo J., Dias A. S., Freitas L. A., Marroni N. P. (2011): Methionine- and choline-deficient diet induces hepatic changes characteristic of non-alcoholic steatohepatitis. Arch. Gastroenterol. 48, 72-79

Mc Clain C. J., Hill D. B., Song Z. (2002): S-adenosylmethionine, cytokines and alcoholic liver disease. Alcohol. 27, 185-192 http://dx.doi.org/10.1016/S0741-8329(02)00224-0

Parson S. M., Prior C., Marshall I. G. (1993): Acetylcholine transport, storage and release. Int. Rev. Neurobiol. 35, 279-290 http://dx.doi.org/10.1016/S0074-7742(08)60572-3

Pavlov V. A., Tracey K. J. (2004): Neural regulators of innate immune responses and inflammation. Cell. Mol. Life. Sci. 61, $2322-2331$ http://dx.doi.org/10.1007/s00018-004-4102-3

Penry J., Manore M. (2008): Choline: an important micronutrient for maximal endurance-exercise performance? Int. J. Sport. Nutr. Exerc. Metab. 18, 191-203

Perrier N. A., Salani M., Falasca C., Bon S., Augusti-Tocco G., Massoulié J. (2005): The readthrough variant of acetylcholinesterase remains very minor after heat shock, organophosphate inhibition and stress in cell culture and in vivo. J. Neurochem. 94, 629-638 http://dx.doi.org/10.1111/j.1471-4159.2005.03140.x 
Prado M. A. M., Reis R. A. M., Prado V., de Mello M. C., Gomez M. V., de Mello F. G. (2002): Regulation of acetylcholine synthesis and storage. Neurochem. Int. 41, 291-299 http://dx.doi.org/10.1016/S0197-0186(02)00044-X

Querfurth H. W., La Ferla F. M. (2010): Alzheimer's disease. N. Engl. J. Med. 362, 329-344 http://dx.doi.org/10.1056/NEJMra0909142

Reardon C., Duncan G. S., Brüstle A. (2013): Lymphocyte-derived Ach regulates local innate but not adaptive immunity. Proc. Natl. Acad. Sci. USA 110, 1410-1415 http://dx.doi.org/10.1073/pnas.1221655110

Rinella M. E., Elias M. S., Smolak R. R., Fu T., Borensztajn J., Green R. M. (2008): Mechanisms of hepatic steatosis in mice fed a lipogenic methionine choline-deficient diet. J. Lipid. Res. 49, 1068-1076 http://dx.doi.org/10.1194/jlr.M800042-JLR200

Ryu J. E., Jo W., Choi H. J., Jang S., Lee H. J., Woo D. C., Kim J. K., Kim K. W., Yu E. S., Son W. C. (2015): Evaluation of nonalcoholic fatty liver disease in C57BL/6J mice by using MRI and histopathologic analyses. Comp Med. 65, 409-415

Selhub J. (2008): Public health significance of elevated homocysteine. Food. Nutr. Bull. 29, 116-125 http://dx.doi.org/10.1177/15648265080292S116

Silman I., Sussman J. (2005): Acetylcholinesterase: ,classical" and ,'non-classical“ functions and pharmacology. Curr. Opin. Pharmacol. 5, 293-302 http://dx.doi.org/10.1016/j.coph.2005.01.014

Smith A. D. (2008): The worldwide challenge of the dementias: a role for B vitamins and homocysteine? Food. Nutr. Bull. 29, $143-172$ http://dx.doi.org/10.1177/15648265080292S119

Stanković M. N., Mladenović D. R., Duričić I., Šobajić S. S., Timić J., Jorgačević B., Aleksić V., Vučević D. B., Ješić-Vukićević R., Radosavljević T. S. (2014): Time-dependent changes and association between liver free fatty acids, serum lipid profile and histological features in mice model of nonalcoholic fatty liver disease. Arch. Med. Res. 45, 116-124 http://dx.doi.org/10.1016/j.arcmed.2013.12.010

Stead L., Brosnan J., Brosnan M, Vance D., Jacobs R. (2006): Is it time to reevaluate methyl balance in humans. Am. J. Clin. Nutr. 83, 5-10

Stefanello F. M., Monteiro S. C., Matté C., Scherer E. B., Netto C. A., Wyse A. T. (2007): Hypermethioninemia increases cerebral acetylcholinesterase activity and impairs memory in rats. Neurochem. Res. 32, 1868-1874 http://dx.doi.org/10.1007/s11064-007-9464-0

Trevisan R., Uliano-Silva M., Pandolfo P., Franco J. L., Brocardo P. S., Santos A. R., Farina M., Rodrigues A. L., Takahashi R.
N., Dafre A. L. (2008): Antioxidant and acetylcholinesterase response to repeated malathion exposure in rat cerebral cortex and hippocampus. Basic. Clin. Pharmacol. Toxicol. 102, 365-369 http://dx.doi.org/10.1111/j.1742-7843.2007.00182.x

Ueland P. M. (2011): Choline and betaine in health and disease. J. Inherit. Metab. Dis. 34, 3-15 http://dx.doi.org/10.1007/s10545-010-9088-4

Valko M., Leibfritz D., Moncol J., Cronin M. T., Mazur M., Telser J. (2007): Free radicals and antioxidants in normal physiological functions and human disease. IJBCB. 39, 44-84 http://dx.doi.org/10.1016/j.biocel.2006.07.001

Vučević D., Petronijević N., Radonjić N., Rasić-Marković A., Mladenović D., Radosavljević T., Hrncić D., Djurić D., Susić V., Djuro M., Stanojlović O. (2009): Acetylcholinesterase as a potential target of acute neurotoxic effects of lindane in rats. Gen. Physiol. Biophys. 28, 18-24

Wang X., Yang Z., Xue B., Shi H. (2011): Activation of the cholinergic antiinflammatory pathway ameliorates obesity-induced inflammation and insulin resistance. Endocrinology 152, 836-846 http://dx.doi.org/10.1210/en.2010-0855

Whittaker V. P., Barker L. A. (1972): The subcellular fractionation of brain tissue with special reference to the preparation of synaptosomes and their component organelles. In: Methods of Neurochemistry. (Ed. R. Fried), Marcel Dekker, Inc., New York

Xia Y., Cheng S., He J. (2011): Effects of subchronic exposure to benzo[a]pyrene $(\mathrm{B}[\mathrm{a}] \mathrm{P})$ on learning and memory, and neurotransmitters in male Sprague-Dawley rat. Neurotoxicology 32, $188-198$ http://dx.doi.org/10.1016/j.neuro.2010.12.015

Yajnik C. S., Deshmukh U. S. (2012): Fetal programming: maternal nutrition and role of one-carbon metabolism. Rev. Endocr. Metab. Disord. 13, 121-127 http://dx.doi.org/10.1007/s11154-012-9214-8

Zeisel S. H. (2000): Choline: Needed for normal development of memory. J. Am. Coll. Nutr. 19, 528-531 http://dx.doi.org/10.1080/07315724.2000.10718976

Zeisel S. H., da Costa K. A. (2009): Choline: an essential nutrient for public health. Nut. Rev. 67, 615-623 http://dx.doi.org/10.1111/j.1753-4887.2009.00246.x

Zhang X. J., Greenberg D. S. (2012): Acetylcholinesterase involvement in apoptosis. Front. Mol. Neurosci. 5, 40 http://dx.doi.org/10.3389/fnmol.2012.00040

Received: July 30, 2015

Final version accepted: December 2, 2015

First published online: May 13, 2016 